\title{
Study of outgoing longwave radiation anomalies associated with Haiti earthquake
}

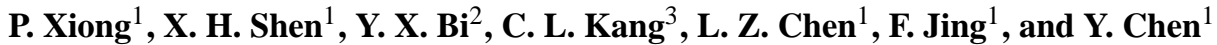 \\ ${ }^{1}$ Institute of Earthquake Science, China Earthquake Administration, Beijing, China \\ ${ }^{2}$ School of Computing and Mathematics, University of Ulster, Newtownabbey, Co. Antrim, UK \\ ${ }^{3}$ China Earthquake Networks Center, China Earthquake Administration, Beijing, China
}

Received: 27 May 2010 - Revised: 17 August 2010 - Accepted: 20 September 2010 - Published: 15 October 2010

\begin{abstract}
The paper presents an analysis by using the methods of Eddy field calculation mean and wavelet maxima to detect seismic anomalies within the outgoing longwave radiation (OLR) data based on time and space. The distinguishing feature of the method of Eddy field calculation mean is that we can calculate "the total sum of the difference value" of "the measured value" between adjacent points, which could highlight the singularity within data. The identified singularities are further validated by wavelet maxima, which using wavelet transformations as data mining tools by computing the maxima that can be used to identify obvious anomalies within OLR data. The two methods has been applied to carry out a comparative analysis of OLR data associated with the earthquake recently occurred in Haiti on 12 January 2010. Combining with the tectonic explanation of spatial and temporal continuity of the abnormal phenomena, the analyzed results have indicated a number of singularities associated with the possible seismic anomalies of the earthquake and from the comparative experiments and analyses by using the two methods, which follow the same time and space, we conclude that the singularities observed from 19 to 24 December 2009 could be the earthquake precursor of Haiti earthquake.
\end{abstract}

\section{Introduction}

Outgoing longwave radiation (OLR) of the Earth is a major driver of the Earth system climate. The reflection, absorption, and emission of this energy occur through a complex system of clouds, aerosols, atmospheric constituents, oceans and land surfaces (Ouzounov et al., 2007). OLR estimates have been obtained since June 1974 from the window

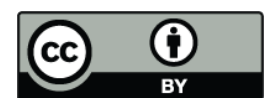

Correspondence to: P. Xiong (xiong.pan@gmail.com) channel measurements of the operational National Oceanographic and Atmospheric Administration (NOAA) polarorbiting satellites (Gruber and Krueger, 1984; Gruber and Winston, 1978). These estimates have been used extensively to study natural disasters, both as one component of the radiation balance of the atmosphere (Ohring and Gruber, 1982) and to infer changes before natural disasters, like earthquakes (Liu et al., 1997).

The techniques to use the OLR estimates have been developed to detect seismic precursors within OLR data prior to earthquakes, which is vitally important to sufficiently make use of OLR resources to monitor stable conditions of active faults beneath the earth and to identify the potential earthquake zones. Liu and Kang have studied the spatial and temporal variability of outgoing long wave radiation before and during major earthquakes using the method of Eddy field calculation mean (Liu et al., 1999), and found that the radiation intension around epicenter district is much more intensive, especially in a short term (one or two month) before earthquakes (Kang and Liu, 2001; Liu, 2000). A analysis based on mathematical statistics and spatial features shows that there are strongly seasonal and regional variations in China using 30 years (1979-2008) OLR data, that is, lower value in Qinghai-Tibet Plateau and higher in northwest and east of China, the variability of OLR in these regions are dramatic in the spring and autumn and relatively smooth in the summer and winter (Feng et al., 2009). More recently, Xiong et al. (2009a, b) have conducted a study to detect OLR anomalous using the method of wavelet maxima, which is introduced by Cervone et al. $(2004,2005)$ as a new data mining methodology based on wavelet transformations and statistical analysis to detect precursory signals associated with earthquakes. The prominent OLR singularities could be found prior to the earthquakes in the wavelet maxima curves, which follow continuity both in space and time based on numerous comparative experiments and analyses of the earthquakes occurred in China (Xiong et al., 2009a, b).

Published by Copernicus Publications on behalf of the European Geosciences Union. 
In this paper, the presented methodology calculates Eddy field, which could highlight the singularity within data, and uses wavelet transformations as data mining tools by computing the wavelet maxima, which could be used to identify obvious anomalies within OLR data. The two methods has been applied to carry out a comparative analysis of OLR data associated with the earthquake recently occurred in Haiti on 12 January 2010. Combining with the tectonic explanation of spatial and temporal continuity of the abnormal phenomena, the analyzed results have indicated a number of singularities associated with the possible seismic anomalies of the earthquake.

\section{Earthquake and data}

In this study, Haiti earthquake of magnitude 7.0 is selected for evaluating the proposed methods. It occurred on 12 January 2010 , the location of the epicenter is at $18.457^{\circ} \mathrm{N}$, $72.533^{\circ} \mathrm{W}$ (Fig. 1a), and the depth is $13 \mathrm{~km}$ (8.1 miles). The main earthquake was followed by a series of smaller aftershocks.

The OLR energy flux is characterized by a number of parameters, such as the emission from the ground, atmosphere and clouds formation, which have been being observed on the top of the atmosphere by National Oceanic and Atmosphere Administration (NOAA) satellites (NCAR and NOAA, 2008). These OLR data have been recorded twice-daily by the several polar-orbiting satellites for more than eight years, forming time series data across the different periods of time along with the spatial coverage of the entire earth. The original OLR data are processed by the interpolation technique to minimize the distance in space or time over which the value is interpolated. The detail of the interpolation technique has been given by Liebmann and Smith (1996).

The NOAA Climate Prediction Center web site (http:// www.cdc.noaa.gov/) provides the daily and monthly OLR data. The OLR algorithm for analyzing the Advanced Very High Resolution Radiometer (AVHRR) data is from Gruber and Krueger (1984), and integrates infrared radiation data between $10 \mu \mathrm{m}$ and $13 \mu \mathrm{m}$. These data are mainly sensitive to near surface and/or cloud temperatures. Our study includes analysis of OLR data used measurements from four AVHRR polar orbiters NOAA-18. The data used for this study are twice-daily means from the NOAA- 18 satellite. Their spatial coverage is $1 \times 1$ degree of latitude by longitude covering the area of $90^{\circ} \mathrm{N}-90^{\circ} \mathrm{S}$ and $0^{\circ} \mathrm{E}-360^{\circ} \mathrm{E}$, and the time range is from 1 February 2009 to 31 February 2010, forming time series data over the specified region.

\section{Methodology}

There are several methods to choose in the analysis of OLR data, mainly including the method of difference value (Kang et al., 2006), the method of the Eddy field calculation mean
(Kang and Liu, 2001; Liu, 2000; Liu et al., 1999), the wavelet time-frequency analysis method (Wang et al., 2008; Xiong et al., 2009a, b; Feng et al., 2009) and the method of std threshold (Feng et al., 2010). In previous study by using these methods, the method of the Eddy field calculation mean calculates Eddy field, which could highlight the singularity within OLR data between adjacent points, and the wavelet time-frequency analysis method is capable of providing the time and frequency information simultaneously, hence giving a time-frequency representation of the signal, that could detect the prominent OLR singularities follow continuity both in space and time. These two methods are more effective and obvious to detect anomalies within OLR data related to earthquake, which is in good accordance with previous study.

In this paper, we have undertaken a comparative analysis using the two methods for our study. The method of Eddy field calculation mean, and the method of wavelet maxima, with the wavelet method of the Daubechies Wavelets, called a db1. We use these two methods to detect singularities within the OLR data in time and space covering the selected earthquake.

\subsection{The method of Eddy field calculation mean}

The Eddy field calculation mean (Kang and Liu, 2001; Liu, 2000; Liu et al., 1999) refers to "the total sum of the difference value" of "the measured value" of OLR data between adjacent points in the current day (month), its expression is

$$
\begin{aligned}
S_{\mathrm{d}}^{*}\left(x_{i, j}, y_{i, j}\right) & =4 \cdot S\left(x_{i, j}, y_{i, j}\right)-\left[S\left(x_{i-1, j}, y_{i, j}\right)\right. \\
& +S\left(x_{i, j}, y_{i, j-1}\right)+S\left(x_{i+1}, y_{i, j}\right) \\
& \left.+S\left(x_{i, j}, y_{i, j+1}\right)\right] .
\end{aligned}
$$

Where $S_{\mathrm{d}}^{*}\left(x_{i, j}, y_{i, j}\right)$ - daily Eddy field; $S\left(x_{i, j}, y_{i, j}\right)$ - daily mean; $x$ - latitude, $y$-longitude; $i, j$ - any number of grid points.

The following describes the experimental procedure and analysis method through an example of the Haiti earthquake using OLR daily data.

First, based on historical seismic activities and tectonic characteristics (Fig. 1a), we define an experimental area in the $10 \times 10$ degree of latitude by longitude area over the epicenter (Fig. 1b). The duration of the OLR data used here is from 1 to 24 January 2010. By calculating daily Eddy field using expression (1) within the selected OLR daily data, and using the method of mesh grid to transform vectors $\boldsymbol{x}$ (latitude) and $\boldsymbol{y}$ (longitude) into arrays X and Y. The rows of the output array X are copies of the vector $x$; columns of the output array $\mathrm{Y}$ are copies of the vector $\boldsymbol{y}$, using the method of 2-D data (arrays $\mathrm{X}$ and $\mathrm{Y}$ ) interpolation returns matrix $\mathbf{C}$ (interpolated Eddy field) containing elements corresponding to the elements of $\mathrm{X}$ and $\mathrm{Y}$ and determined by interpolation within the 2-D function specified by matrices $\mathbf{X}, \mathbf{Y}$, and $\mathbf{Z}$ (Eddy field), the interpolation method we used here is Cubic interpolation, as long as data is uniformly-spaced. 

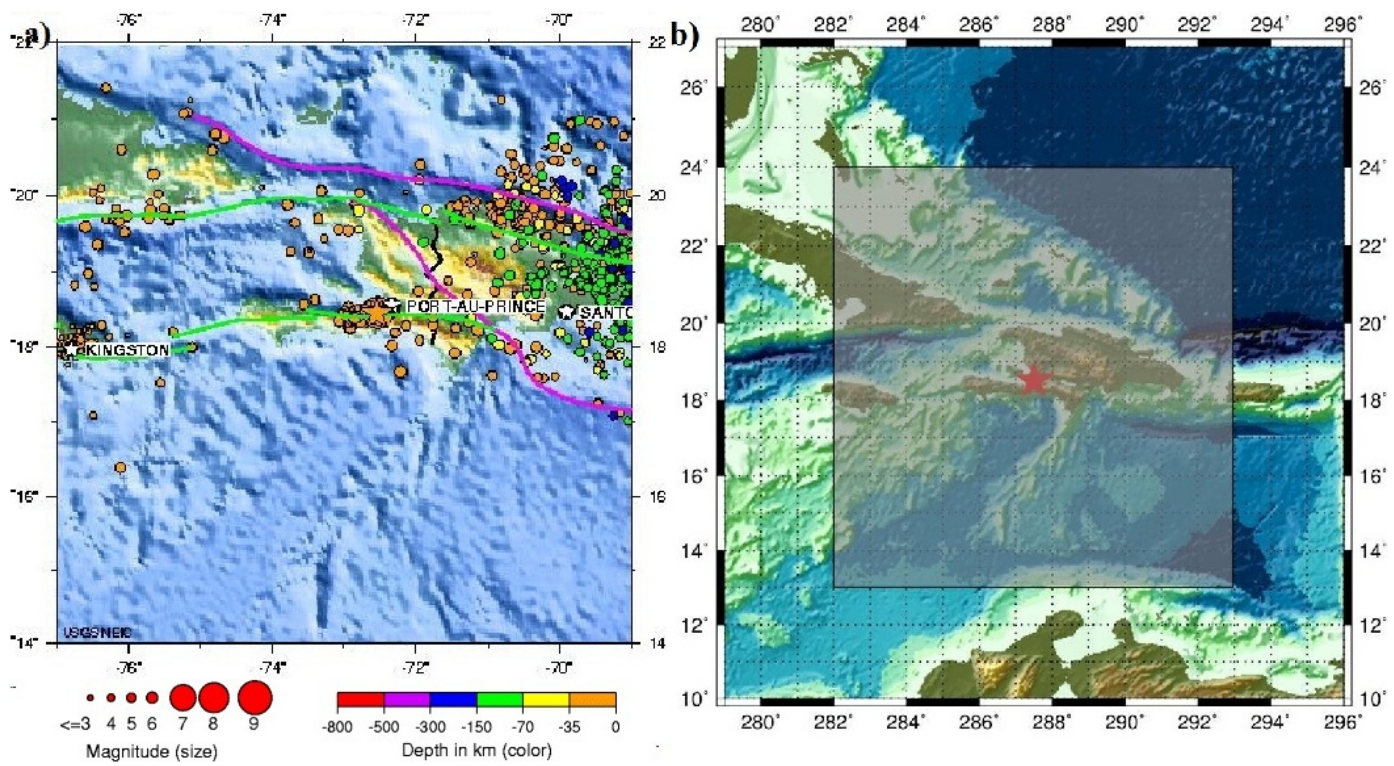

Fig. 1. (a) Historic seismicity (1990 to Present) of Haiti region. The epicenter of Haiti earthquake is marked with a star. The major tectonic boundaries (Subduction Zones - purple, Ridges - red and Transform Faults - green) are also indicated (source: USGS). (b) Map of the region of the earthquake. The epicenter is marked with a red star. The grids used in the experiment are indicated in gray.

With shading interpolation function (varies the color in each line segment and face by interpolating the color map index or true color value across the line or face), each cell in matrix $\mathbf{C}$ (interpolated Eddy field) is colored by bilinear interpolation of the colors at its four vertices. The minimum and maximum elements of $\mathbf{C}$ are assigned the first and last colors in the color map. Colors for the remaining elements in $\mathbf{C}$ are determined by a linear mapping from value to color map element, and we can get the daily Eddy field map by drawing a pseudo color plot of the elements of $\mathbf{C}$ at the locations specified by $\mathbf{X}$ and $\mathbf{Y}$.

Second, we rearrange every Eddy daily field curve onto one diagram to form Eddy OLR curves of January 2010 as shown in Fig. 2. In the figure the $x$-axis of each Eddy OLR curve represents longitude, and the $y$-axis of each Eddy OLR curve represents latitude. The magnitudes of color map represent the degrees of intensity where the larger the magnitude, the higher the degree of intensity. The figure heading lists date of the used OLR daily data, epicenter is marked with red star, tectonic plate boundaries with white line.

Final stage is to identify variability from the Eddy field curves. The key feature of variability is that they appear near epicenter with a large magnitude. In Fig. 2, we can find several variability, which can be grouped into three types pre- and post-earthquake and when the earthquake occurred, corresponding to (1) variability prior to the earthquake, several high value variability appears around the epicenter, such as Eddy daily field of 4, 8 and 11 January 2010 in Fig. 2a, which may be caused by the large energy flux before the Haiti earthquake; (2) variability in the time when the earthquake occurred, such as Eddy daily field of 12 January 2010 in
Fig. 2a, which may be caused by the release of a large amount of energy; (3) variability after the earthquake, such as Eddy daily field from 13 to 16 January 2010 in Fig. 2b, perhaps caused by many aftershocks after the earthquake.

\subsection{The method of wavelet maxima}

The basic theory of wavelet transformation and singularities calculation based on wavelet maxima has been described in the references (Grossman and Morlet, 1984; Mallat and Hwang, 1992), and the detail description of the experimental procedure of the method of wavelet maxima has been given in the references (Xiong et al., 2009a, b). In this paper, for studying seismic impact on spatial extent, we carried out a new experiment by enlarging spatial extent of experimental area.

First, we define an experimental area. By taking into account the tectonic background, continental boundaries and active faults (Fig. 1a), we define an experimental area and divide it into a set of grids of $3 \times 3$ degree of latitude by longitude area over the epicenter, use the method of wavelet maxima (Xiong et al., 2009a, b), we can get wavelet maxima curves.

By enlarging spatial extent of experimental area, we divide the experimental area into a set of grids from $5 \times 5$ degree of latitude by longitude area over the epicenter to $9 \times 9$ degree of latitude by longitude area over the epicenter.

Second, based on the defined grids, OLR daily data, from 1 February 2009 to 31 February 2010, are downloaded from the NOAA Climate Prediction Center. After pre-processing, we employ the wavelet method $\mathrm{db} 1$ to analyze the data and generate wavelet maxima curves. The scale of wavelet 

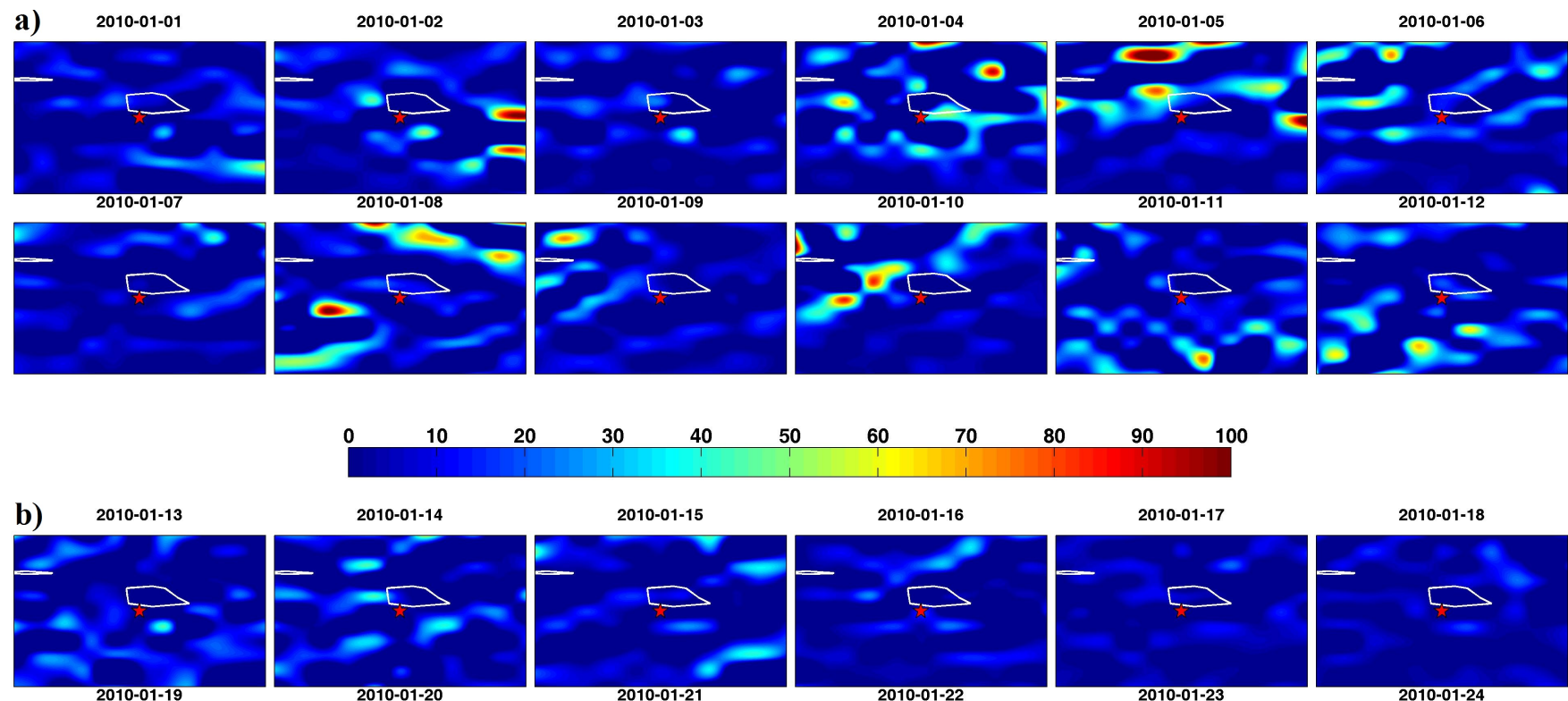

$40 \quad 50$
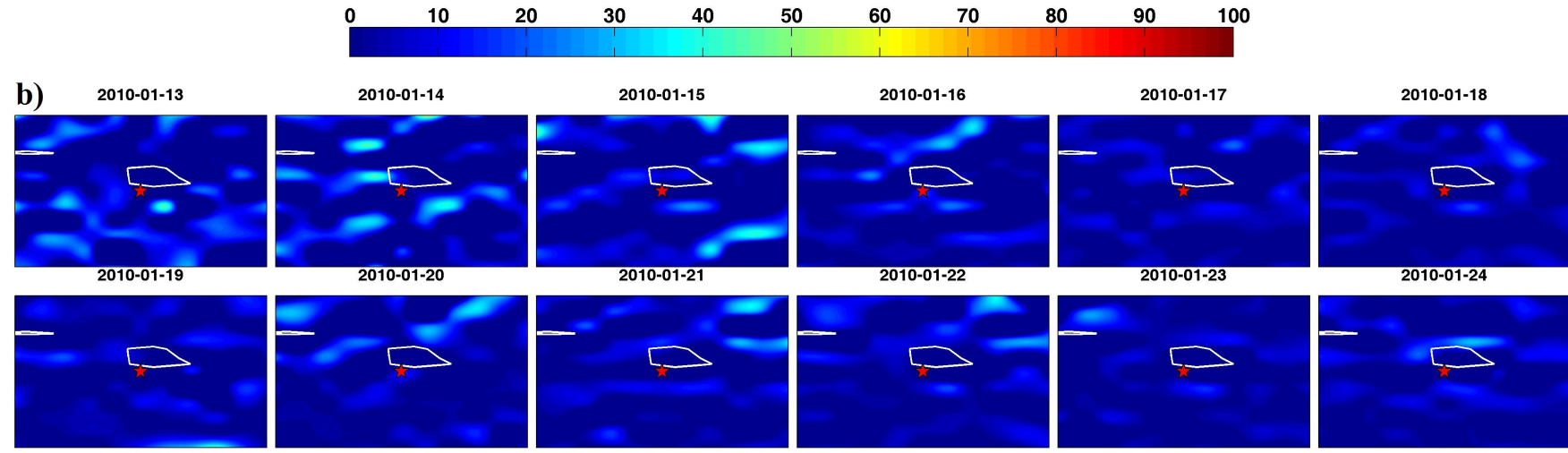

Fig. 2. Eddy field OLR (day data) curves (a) from 1 to 12 January 2010, before Haiti earthquake, (b) from 13 to 24 January 2010 , after Haiti earthquake. Epicenter is marked with red star, tectonic plate boundaries with white line, Longitude from $282.5^{\circ}$ to $292.5^{\circ}$, Latitude from $13.5^{\circ} \mathrm{N}$ to $23.5^{\circ} \mathrm{N}$.

method here we used is 16 , so the corresponding maxima columns are 16 each time. To get maxima more effectively and easy for visualize, we calculate the mean value of maxima each time/row, so the maxima column become 1 each time. In the same spirit, we use the same method to calculate the corresponding maxima of the experimental area with a set of grids from $5 \times 5$ degree of latitude by longitude area over the epicenter to $9 \times 9$ degree of latitude by longitude area over the epicenter.

Third, analyze the result using the method of wavelet maxima. The result of the new experiment indicated that the time when singularity appeared is consistency in different spatial scales, which will be discussed in next section.

\section{Results and discussion}

1. Using the method of Eddy field calculation mean, with the OLR data from 1 to 24 January 2010. We get Eddy field OLR (day data) curves (Fig. 2) and Eddy field OLR (night data) curves (Fig. 3) from 1 to 24 January 2010, the Epicenter is marked with red star, tectonic plate boundaries with white line, Longitude is from $282.5^{\circ}$ to $292.5^{\circ}$ and Latitude is from $13.5^{\circ} \mathrm{N}$ to $23.5^{\circ} \mathrm{N}$.

From Fig. 3a several singularities are identified before Haiti earthquake, all of them are around the Haiti earthquake epicenter. These singularities may be caused by the large amount of energy generated by the Haiti earthquake, and singularities in the day when the earthquake occurred, which may be caused by the release of a large amount of energy; after the earthquake (Fig. 3b), in Eddy daily field of 20 and 21 January 2010, obvious singularities could be observed, which perhaps caused by many aftershocks after Haiti earthquake.

Compared with Fig. 2, the distribution of the singularities before earthquake in Fig. $3 \mathrm{a}$ is similar to that in Fig. 2a, but the Eddy OLR curves before earthquake in Fig. 3a are more disorder with larger magnitudes, and singularity in the day when the earthquake occurred (12 January 2010) could be clearly observed, we conclude the cause could be due to that the time that earthquakes occurred is at night.

2. In order to examine the result by the method of Eddy field calculation mean above, by enlarging spatial extent from $3 \times 3$ degree of latitude by longitude area over the epicenter to $9 \times 9$ degree of latitude by longitude area over the epicenter, we get wavelet maxima curves of a set of grids of $3 \times 3$ degree of latitude by longitude area over the epicenter (Fig. 4), wavelet maxima curves of a set of grids of $5 \times 5$ degree of latitude by longitude area over the epicenter (Fig. 5), wavelet maxima curves of a set of grids of $7 \times 7$ degree of latitude by longitude area 

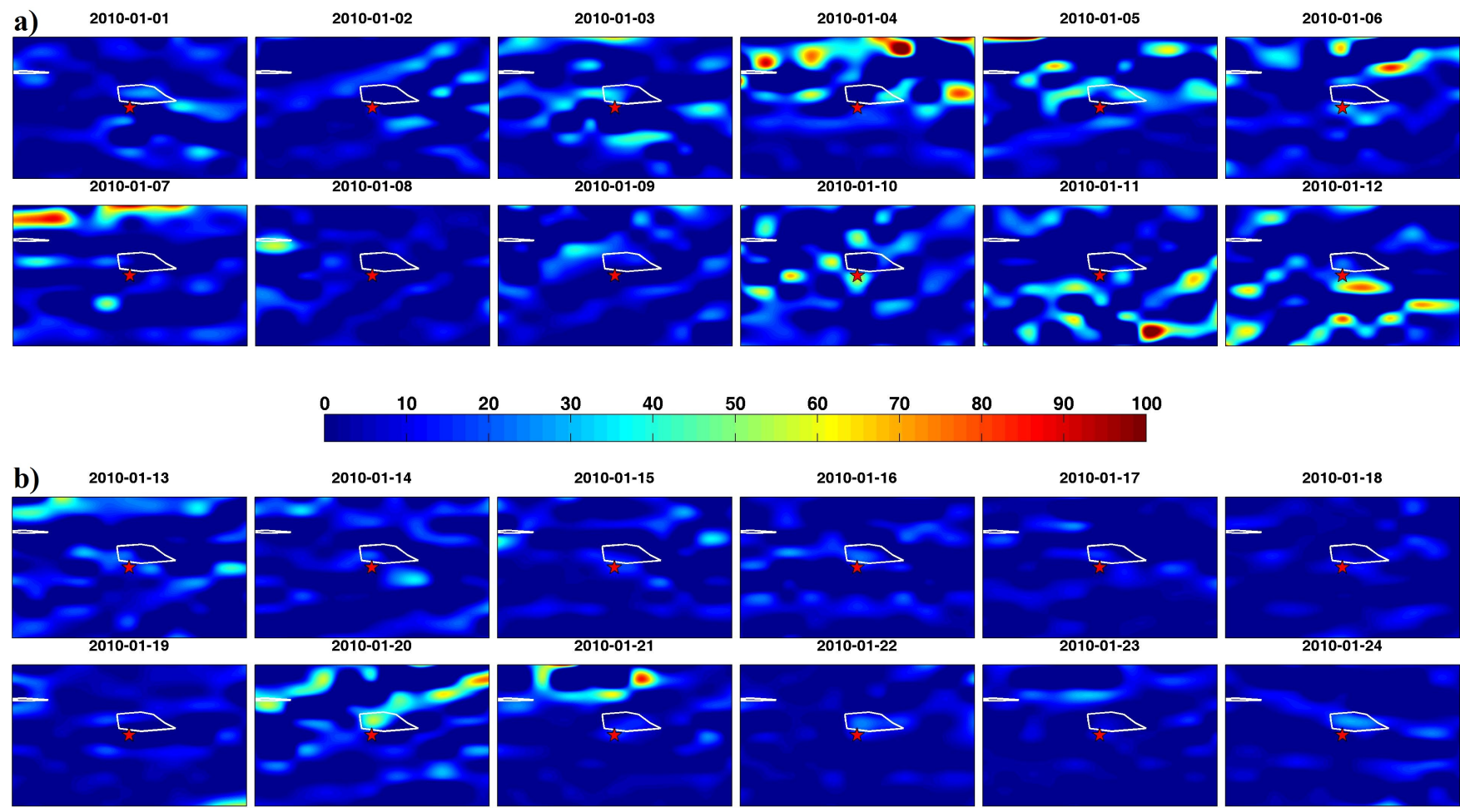

Fig. 3. Eddy field OLR (night data) curves (a) from 1 to 12 January 2010, before Haiti earthquake, (b) from 13 to 24 January 2010 , after Haiti earthquake. Epicenter is marked with red star, tectonic plate boundaries with white line, Longitude from $282.5^{\circ}$ to $292.5^{\circ}$, Latitude from $13.5^{\circ} \mathrm{N}$ to $23.5^{\circ} \mathrm{N}$.

over the epicenter (Fig. 6) and wavelet maxima curves of a set of grids of $9 \times 9$ degree of latitude by longitude area over the epicenter (Fig. 7).

From Fig. 4, the location of study girds is from $17^{\circ} \mathrm{N}$, $286^{\circ} \mathrm{E}$ to $20^{\circ} \mathrm{N}, 289^{\circ} \mathrm{E}$, it can be seen that the distribution of singularities is discontinuous and disorder, all of the singularities are not obvious except one before earthquake, which is around December 2009, about one month before Haiti earthquake. Around the earthquake, no obvious singularities could be observed, which is differ from the results using the method of Eddy field calculation mean.

In order to examine the reliability of the result of wavelet maxima analysis curves of a set of grids of $3 \times 3$ degree of latitude by longitude area over the epicenter and study seismic impact on spatial extent, we get wavelet maxima curves of a set of grids of $5 \times 5$ degree of latitude by longitude area over the epicenter (Fig. 5) by enlarging spatial extent of experimental area, which is wavelet maxima curves from Grid1 to Grid25, the location which is from $16^{\circ} \mathrm{N}, 285^{\circ} \mathrm{E}$ to $21^{\circ} \mathrm{N}, 290^{\circ} \mathrm{E}$.

The singularities in Fig. 5 are not obvious but one continuous and obvious singularity could be also observed around December 2009, which is the same as in Fig. 4.
Comparing Fig. 5 with Fig. 4, the distribution of the singularities is similar, but singularities in Fig. 5 are more disorder with smaller magnitudes, a possible reason for this is the spatial extent in Fig.5 is larger, resulting in a smaller distribution of average energy in experimental areas.

To get more persuasive experimental results, we continue to enlarge spatial extent of experimental area to $7 \times 7$ degree of latitude by longitude area over the epicenter (Fig. 6) and $9 \times 9$ degree of latitude by longitude area over the epicenter (Fig. 7), the location of which are from $15^{\circ} \mathrm{N}, 284^{\circ} \mathrm{E}$ to $22^{\circ} \mathrm{N}, 291^{\circ} \mathrm{E}$ and $14^{\circ} \mathrm{N}, 283^{\circ} \mathrm{E}$ to $23^{\circ} \mathrm{N}, 292^{\circ} \mathrm{E}$, respectively.

Compared with Fig. 4 and Fig. 5, the feature of the singularities in the wavelet maxima curves from $7 \times 7$ degree of latitude by longitude area over the epicenter (Fig. 6) and the wavelet maxima curves $9 \times 9$ degree of latitude by longitude area over the epicenter (Fig. 7) is similar, which could be summarized as follows:

1. The singularities in Figs. 6 and 7 are not obvious but one continuous and obvious singularity is around December 2009, which is the same as Figs. 4 and 5. 


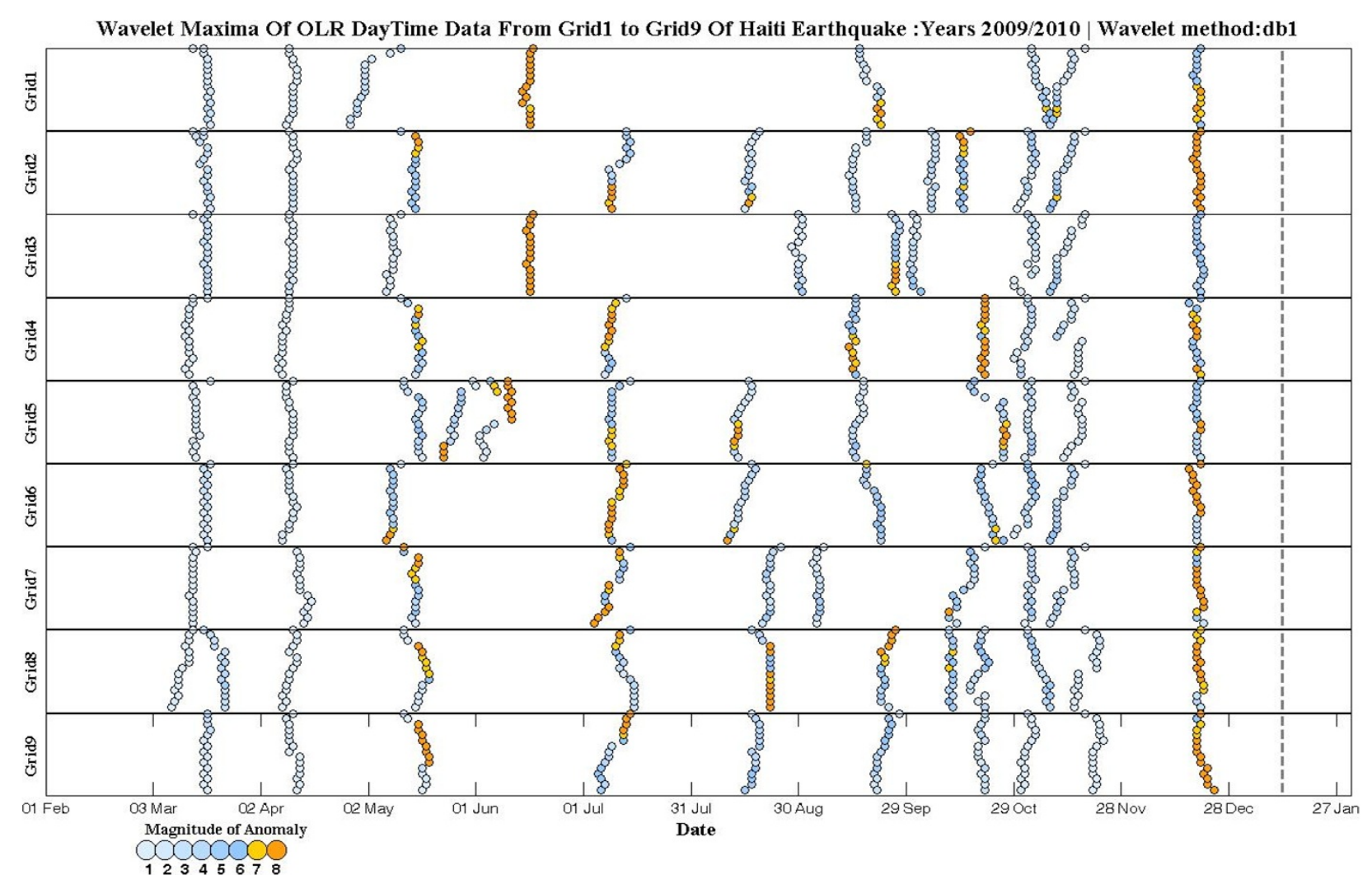

Fig. 4. Wavelet maxima analysis curves from Grid1 to Grid9, with a set of grids of $3 \times 3$ degree of latitude by longitude area over the epicenter, the dashed line indicates the day when the earthquake occurred.

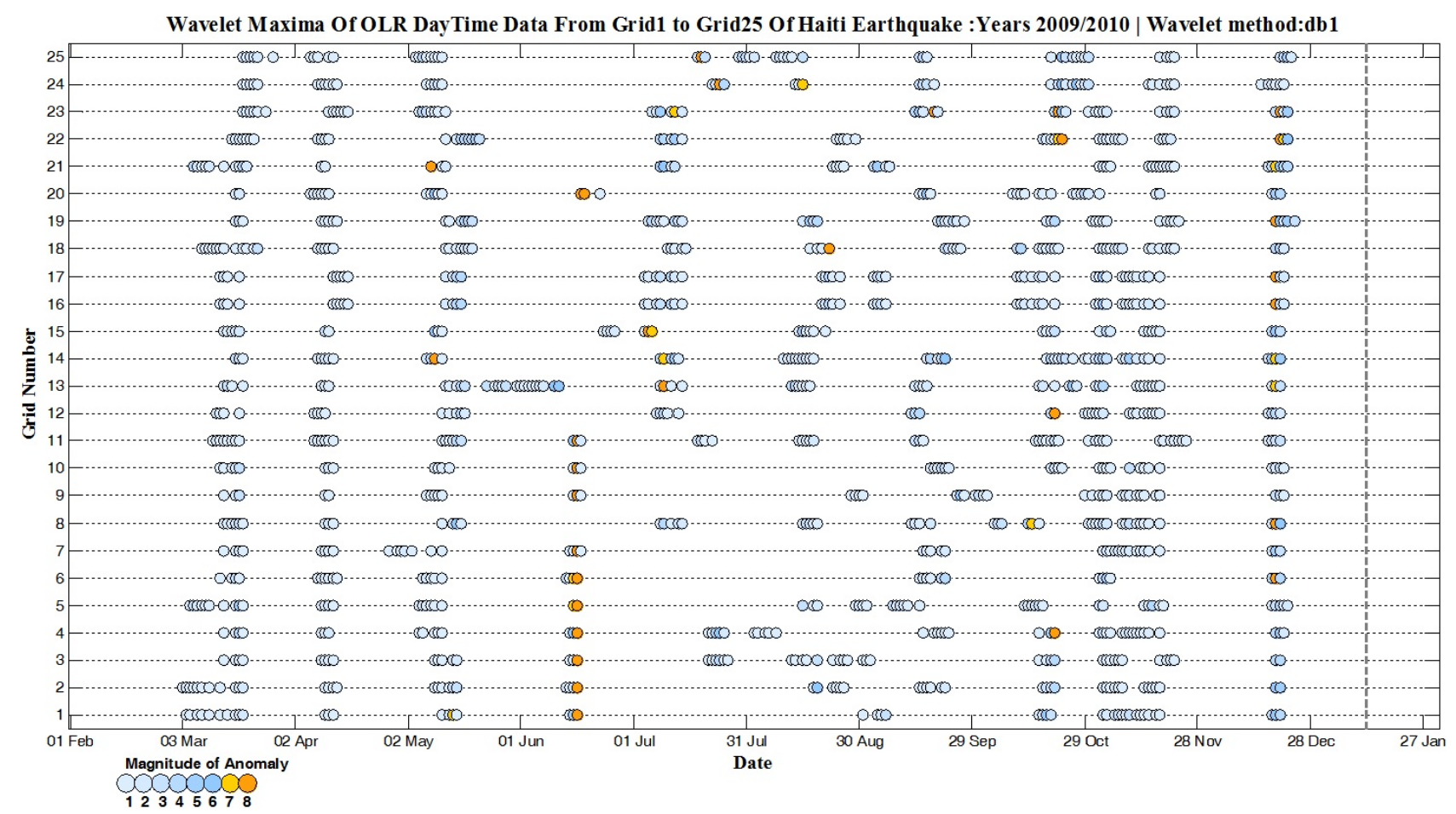

Fig. 5. Wavelet maxima analysis curves from Grid1 to Grid25, with a set of grids of $5 \times 5$ degree of latitude by longitude area over the epicenter, the dashed line indicates the day when the earthquake occurred. 


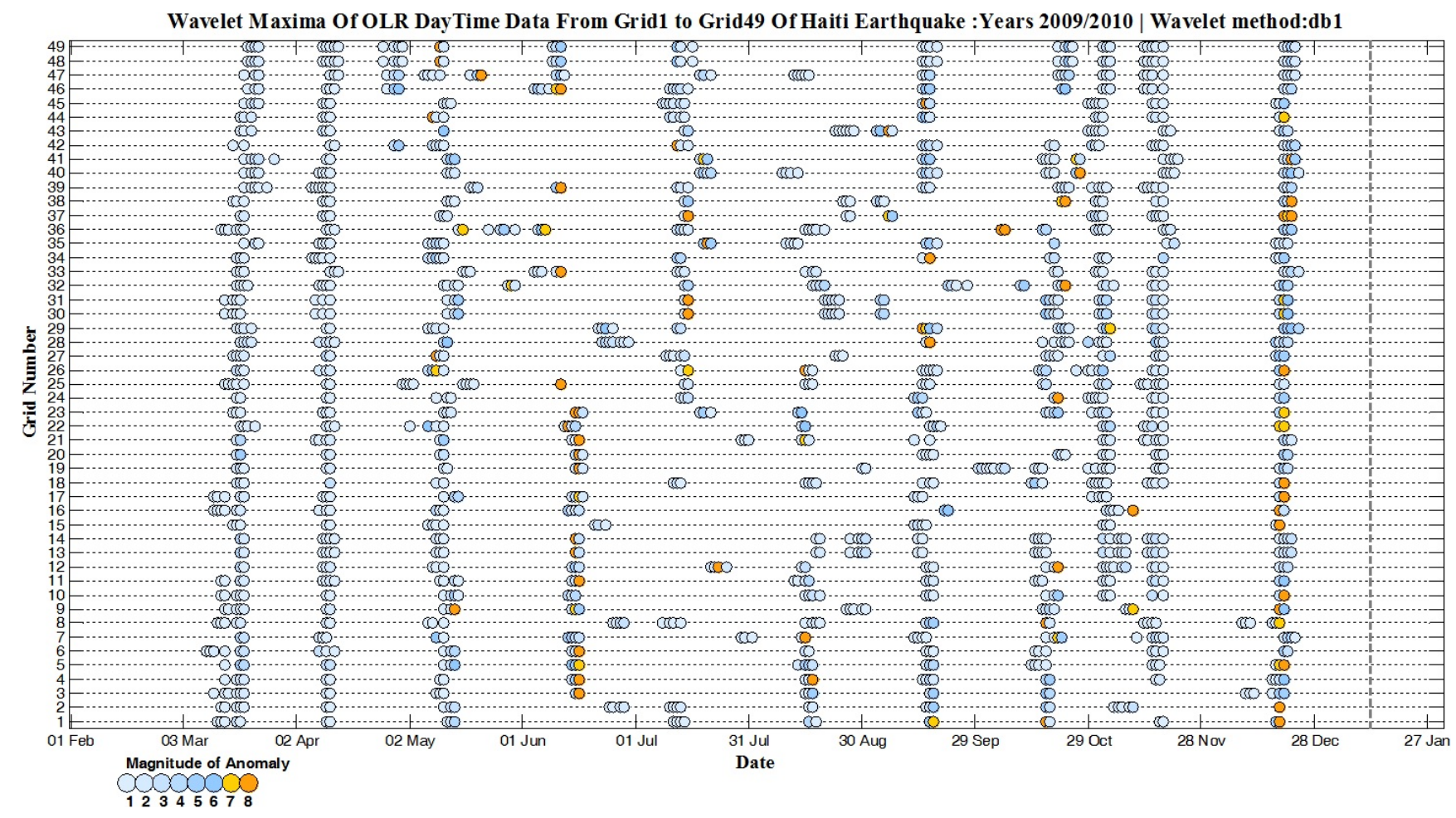

Fig. 6. Wavelet maxima analysis curves from Grid1 to Grid49, with a set of grids of $7 \times 7$ degree of latitude by longitude area over the epicenter, the dashed line indicates the day when the earthquake occurred.

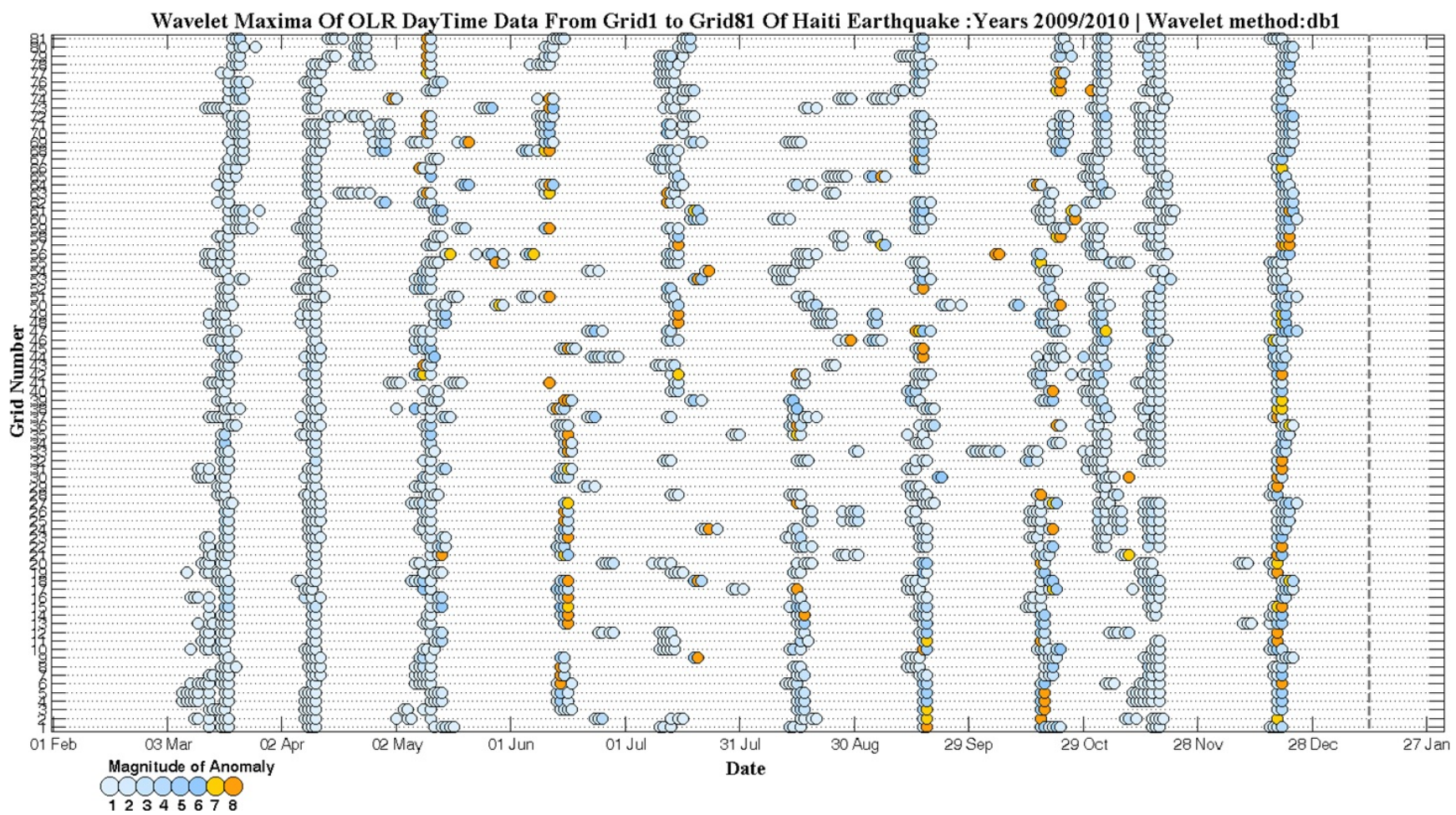

Fig. 7. Wavelet maxima analysis curves from Grid1 to Grid81, with a set of grids of $9 \times 9$ degree of latitude by longitude area over the epicenter, the dashed line indicates the day when the earthquake occurred. 

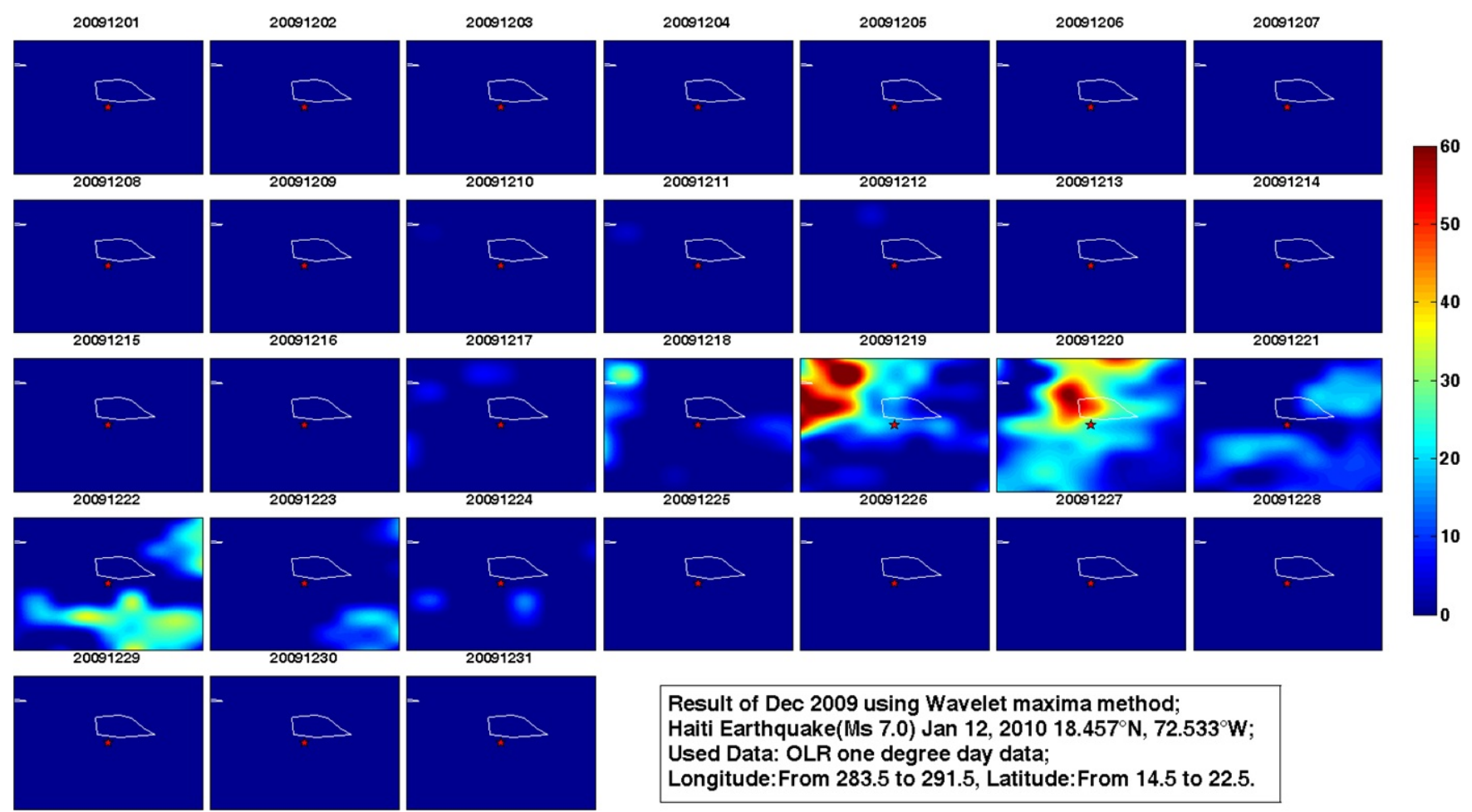

Result of Dec 2009 using Wavelet maxima method;

Haiti Earthquake(Ms 7.0) Jan 12, $201018.457^{\circ} \mathrm{N}, 72.533^{\circ} \mathrm{W}$;

Used Data: OLR one degree day data;

Longitude:From 283.5 to 291.5 , Latitude:From 14.5 to 22.5 .

Fig. 8. Wavelet maxima curves based on spatial continuity analysis of December 2009. Epicenter is marked with red star, tectonic plate boundaries with white line.

2. Comparing Figs. 4 and 5, the distribution of the singularities from Figs. 6 and 7 is similar, but more disorder with smaller magnitudes.

From above discussion, one similar result from Fig. 4 to Fig. 7 could be extracted is that one continuous and obvious singularity around December 2009. To get more visual result, we used the OLR day data of December 2009 to draw wavelet maxima curves based on spatial continuity analysis (Fig. 8).

From Fig. 8, singularities form 19 to 24 December 2009 could be obviously observed, the largest magnitude of singularities appear on 20 December 2009 and gradually weaken after 20 December, thus we postulated that such effect would result from the large energy flux before the Haiti earthquake.

In order to validate the postulate above, we get Eddy field OLR (day data) curves of December 2009 (Fig. 9), and several singularities can identified form 19 to 24 December 2009 in Eddy field OLR (day data) curves of December 2009 (Fig. 9), all of them are around the Haiti earthquake epicenter, the distribution of the singularities is similar as in Fig. 8.

\section{Conclusions}

This paper presents an analysis on the selected OLR data associated with the Haiti earthquake and explains how the OLR singularities discovered which could be related to the earthquakes.

The methodology of wavelet maxima discussed in the present paper uses data mining techniques, including wavelet transformations and spatial/temporal continuity analysis of the wavelet maxima to identify singularities before the earthquakes. Compared with the method of wavelet maxima, the method of Eddy field calculation mean appears also be effective in detecting seismic anomalies in the OLR data, which is more visual to detect OLR anomalies before earthquake.

The conclusion using the two methods is similar, which could be summarized as follows: several singularities may be caused by the large amount of energy generated are identified before Haiti earthquake, and singularities in the day when the earthquake occurred also could be detected, which may be caused by the release of a large amount of energy; after the earthquake obvious singularities could be observed, which perhaps caused by many aftershocks after the earthquake. And from the comparative experiments and analyses using the two methods, which follow the same time 

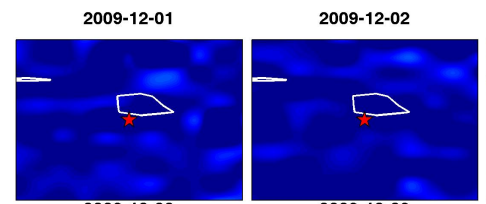

2009-12-0

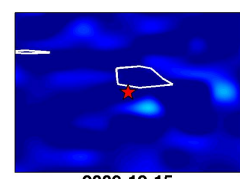

2009-12-15

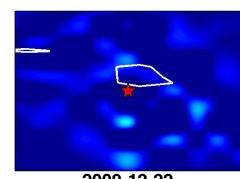

2009-12-22
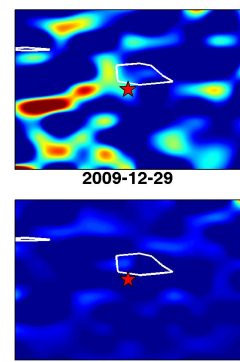

2009-12-16

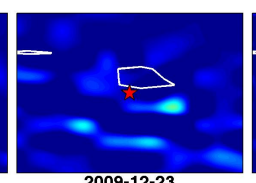

2009-12-23

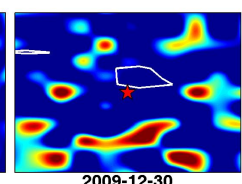

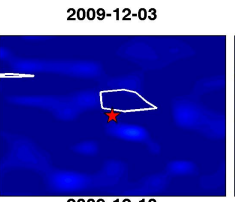
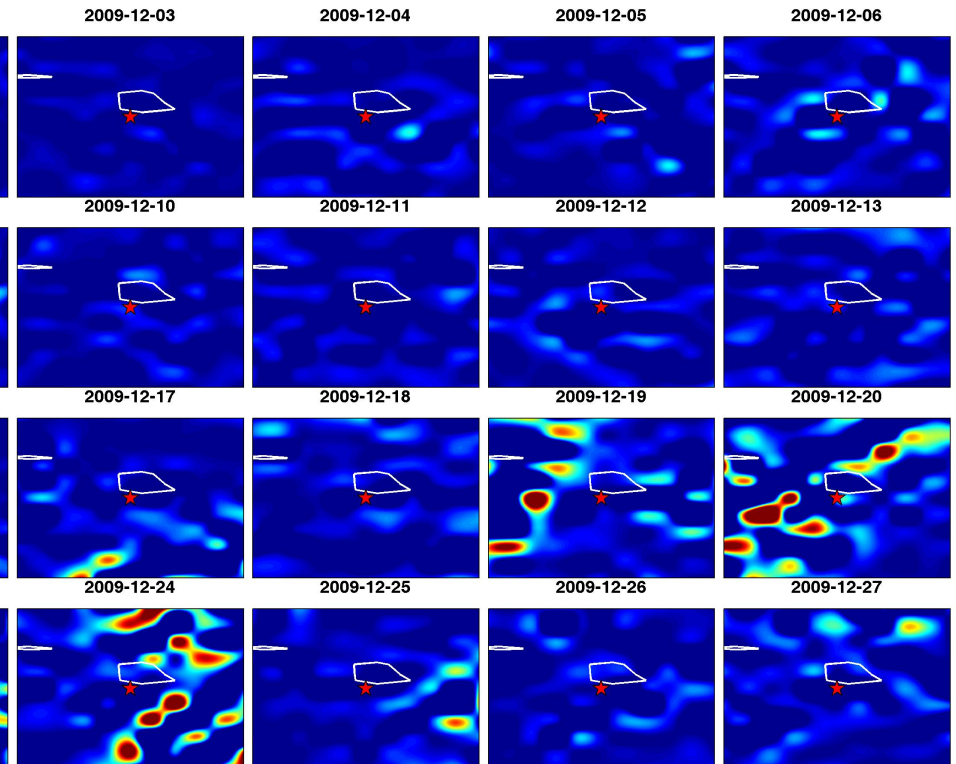

2009-12-25
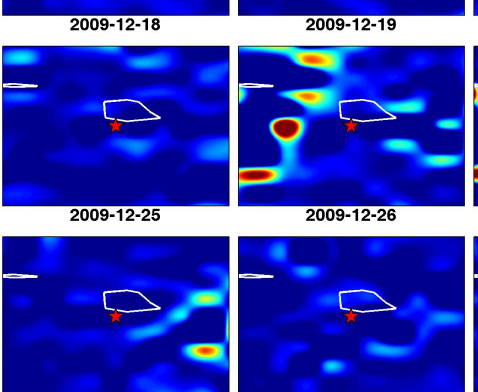

2009-12-26
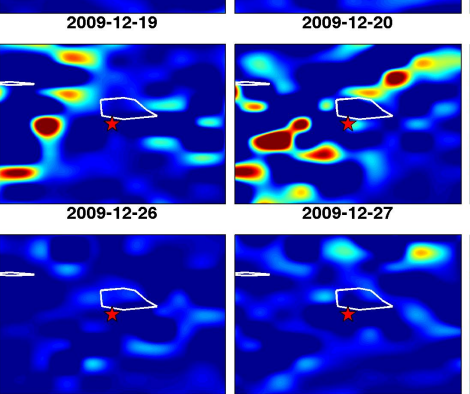

Result of Dec 2009 using Voricity method;

Used Data: OLR one degree day data;

Longitude:From 282.5 to 292.5 , Latitude:From 13.5 to 23.5 .

Fig. 9. Eddy field OLR (day data) curves of December 2009, for Haiti earthquake, epicenter is marked with red star, tectonic plate boundaries with white line.

and space, we conclude that the singularities observed from 19 to 24 December 2009 could be the earthquake precursor of Haiti earthquakes.

Therefore our studies provide a finding that singularities discovered within OLR data could be regarded as an effective indicator to detect seismic anomalies. This finding will be further validated by using more earthquake data in the future.

Acknowledgements. This work is supported by the project of "Study of earthquake integrated identified index and method based on multiple parameters of satellite infrared remote sensing (founded by the Ministry of Science and Technology of China, Grant No.: 2008BAC35B03-05)" and the project of "Data Mining with Multiple Parameters Constraint for Earthquake Prediction (founded by the Ministry of Science and Technology of China, Grant No.: 2008BAC35B05)". The authors would like to acknowledge NOAA for making OLR data available for various research communities, and thank Daya Shanker and another referee for assisting in evaluating this paper.

Edited by: M. E. Contadakis

Reviewed by: D. Shanker and another anonymous referee

\section{References}

Cervone, G., Kafatos, M., Napoletani, D., and Singh, R. P.: Wavelet maxima curves of surface latent heat flux associated with two recent Greek earthquakes, Nat. Hazards Earth Syst. Sci., 4, 359374, doi:10.5194/nhess-4-359-2004, 2004.

Cervone, G., Singh, R. P., Kafatos, M., and Yu, C.: Wavelet maxima curves of surface latent heat flux anomalies associated with Indian earthquakes, Nat. Hazards Earth Syst. Sci., 5, 87-99, doi:10.5194/nhess-5-87-2005, 2005.

Jing, F. Gu, X. Shen, et al.: Study on outgoing longwave radiation variations associated with strong earthquake, Proc. SPIE, 7651, 765113, doi:10.1117/12.855573, 2009.

Jing, F., Shen, X., Kang, C., et al.: Extracting seismic anomalies based on std threshold method using outgoing Longwave radiation data, IGARSS2010, 2010.

Jing, F., Shen, X., Kang, C., et al.: Preliminary Analysis of the Background Features of Outgoing Longwave Radiation in China, Earthquake, 29, 90-97, 2009.

Grossman, A. and Morlet, J.: Decomposition of hardy functions into square integrable wavelets of constant shape, SIAM J. Math. Anal., 15, 723-736, 1984.

Gruber, A. and Krueger, A. F.: The status of the NOAA outgoing longwave radiation data set, B. Am. Meteorol. Soc., 65, 958-962, 1984.

Gruber, A. and Winston, J. S.: Earth-atmosphere radiative heating based on NOAA scanning radiometer measurements, B. Am. Meteorol. Soc, 59, 1570-1573, 1978. 
Kang, C. and Liu, D.: The applicability of satellite remote sensing in monitoring earthquake, Science of Surveying and Mapping, 26(3), 46-48, 2001 (in Chinese with English abstract).

Kang, C., Liu, D., Chen, Y., et al.: Research on Earthquake Prediction Method in North China Using Outgoing Longwave Radiation Information, Northwest. Seismol. J., 28, 59-63, 2006.

Liebmann, B. and Smith, C. A.: Description of a Complete (Interpolated) Outgoing Longwave Radiation Dataset, B. Am. Meteorol. Soc., 77, 1275-1277, 1996.

Liu, D., Luo, Z., and Peng, K.: OLR anomalous phenomena before strong earthquakes, Earthquake, 17(2), 126-132, 1997 (in Chinese with English abstract).

Liu, D., Peng, K., Liu, W., et al.: Thermal omens before earthquake, Acta Seismologica Sinica, 12(6), 710-715, 1999 (in Chinese with English abstract).

Liu, D.: Anomalies analyses on satellite remote sensing OLR before Jiji earthquake of Taiwan Province, Geo-Information Science, 2(1), 33-36, 2000 (in Chinese with English abstract).
Mallat, S. and Hwang, W. L.: Singularity Detection And Processing With Wavelets, IEEE T. Inform. Theory, 38, 617-643, 1992.

NCAR and NOAA:NOAA Interpolated Outgoing Longwave Radiation, available at: http://www.esrl.noaa.gov/psd/data/gridded/ data.interp_OLR.html, 2008.

Ohring, G. and Gruber, A.: Satellite radiation observations and climate theory, Adv. Geophys., 25, 237-304, 1982.

Ouzounov, D., Liu, D., Kang, C., et al.: Outgoing long wave radiation variability from IR satellite data prior to major earthquakes, Tectonophysics, 431, 211-220, 2007.

Wang, Y., Chen, G., Kang, C., et al.: Earthquake-related thermalinfrared abnormity detection with wavelet packet decomposition, Progress in Geophysics, 23(2), 368-374, 2008.

Xiong, P., Bi, Y., and Shen, X.: A Wavelet-based Method for Detecting Seismic Anomalies in Remote Sensing satellite data, MLDM 2009, LNAI 5632, 569-581, 2009a.

Xiong, P., Bi, Y., and Shen, X.: Study of Outgoing Longwave Radiation Anomalies Associated with Two Earthquakes in China using Wavelet Maxima, HAIS 2009, LNAI 5572, 77-87, 2009b. 